\title{
The Relationship Between Sleep Disorders and Quality of Life in Rotating Shift Workers at a Textile Factory
}

\author{
Kamran Ghods, ${ }^{1}$ Abolfazl Abdoallahpour, ${ }^{1}$ Mina Ahmadi, ${ }^{2}$ Majid Mirmohammadkhani, ${ }^{3}$ Ali Gohari, \\ Alireza Emadi, ${ }^{4}$ and Daryoush Pahlevan ${ }^{3,}{ }^{*}$ \\ ${ }^{1}$ Clinical Research Development Unit, Kowsar hospital, Semnan University of Medical Sciences, Semnan, Iran \\ ${ }^{2}$ Student Research Committee, Faculty of Medicine, Semnan University of Medical Sciences, Semnan, Iran \\ ${ }^{3}$ Social Determinants of Health Research Center, Semnan University of Medical Sciences, Semnan, Iran \\ ${ }^{4}$ Deputy of Research and Technology, Semnan University of Medical Sciences, Semnan, Iran \\ "Corresponding author: Daryoush Pahlevan, Social Determinants of Health Research Center, Semnan University of Medical Sciences, Semnan, Iran. Tel/Fax: +98-23 33654177, \\ E-mail: pahlevan.da@gmail.com
}

Received 2017 May 06; Accepted 2017 May 12.

\begin{abstract}
Background: There is no doubt that problems during wakefulness can affect the quality and length of sleep. Sleep disturbances can have a serious negative effect on a person's ability, function, and overall well-being. One of the most important issues that can result in sleep disturbances is professional causes, and the most important of which is shift work. The present study aimed at investigating the association between shift work and various sleep disorders and quality of life.

Methods: This was a cross-sectional study. The data were collected using the Persian version of Epworth sleepiness scale andSF-36 questionnaires to assess the participants' sleep disorder and quality of life. The questionnaires were filled in by 207 shift workers. Age, gender, shift works experience, and working experience were recorded for all participants.

Results: In total, 45 (21.7\%) out of 207 participants were male and 162 (78.3\%) were female. The mean \pm SD age of participants was $25.71 \pm 4.38$ years. The mean \pm SD shift works experience and working experience were $3.76 \pm 3.75$ and $4.68 \pm 3.92$, respectively. Females were more at risk for sleep problems caused by shift work than males $(\mathrm{P}=0.006)$. The prevalence of problems in initiating sleep, frequent waking from sleep, and early morning awakening was more common among shift workers, respectively. A significant negative correlation was found between quality of life and Epworth sleep score, meaning that with the increase in Epworth Sleep Score the quality of life was reduced, and the quality of life was improved by reduction in Epworth sleep score $(\mathrm{r}=-0.5, \mathrm{P}=0.001)$. Conclusions: Higher prevalence of insomnia and poor sleep quality among shift workers and the subsequent reduction in their quality of life based on in this study emphasizes the importance of paying serious attention to sleep disorders in shift workers.
\end{abstract}

Keywords: Shift Work, Sleep Disorders, Quality of Life

\section{Background}

Today's modern society is changing rapidly with respect to economic, social, and personal behavior (1). The competitiveness of the industry and progress of technology have encouraged the industry makers to use their employees for evening and night shifts. Despite the fact that the shift work is very beneficial for the general population, the shift worker is largely influenced by its complications. Studies have shown that shift work causes changes in the normal physiology of the body and has many adverse effects on physical and mental health of the individual (2$4)$. The most common complaint among shift workers is sleep disorders $(5,6)$. In many studies, the prevalence of sleep disorders and sleep quality in shift workers has been investigated $(6,7)$. As sleep is a necessity of life and any impairment in the quality and quantity of sleep can have obvious and serious adverse effects on performance, ability, and health, thus the study of sleep disorders, their causes, and the ways to minimize these problems in shift workers is of particular importance (8).

Quality of life includes the difference and distance of physical, mental, emotional, and social condition of a person at the moment compared to the expectations and aspirations of his/her life (9). Given that sleep is a critical element affecting the health and quality of people's life, this study aimed at examining the relationship between sleep disorders in shift workers and their quality of life.

Patients who have shift work sleep disorders (SWSD) mainly suffer from insomnia or excessive sleepiness when the conditions for proper sleep and other sleep disorders do not exist (10). Partial sleep, early waking up, and drowsiness during the early morning hours are of people's sleep disorders symptoms associated with shift work $(11,12)$. Risks of SWSD factors include natural and intrinsic reasons, and incompatibility with little sleep at night, starting-up shifts in old ages, being female, short period 
of rotating shifts, and lack of time to cope with the shift, rotating shifts, rotating shifts that change fast, or working counter-clockwise $(10,13)$.

Night shifts result in lack of coordination in body's internal circadian rhythm with environmental factors regulating the body's biologic clock such as light-dark cycle, and this leads to disruption of normal physiological activity and psychological difficulties $(14,15)$. Changing shift work from day to evening and night causes a person to regulate his/her sleep-wake cycle in accordance with the job duties and not based on the natural rhythms and physiological body. Although the body can gradually change its circadian rhythm to coordinate with individual's sleepwake cycle, except very few exceptions, this coordination will not be $100 \%$ (16). Particularly in those who work in rotating shift works, the circadian rhythm of the body loses this chance to adapt with working hours, which is constantly changing. As a result of this incompatibility, a condition known as delayed sleep phase syndrome (Shift Lag) occurs; this is characterized by fatigue, drowsiness, insomnia, digestive problems, irritability, decreased mental activity, and individual performance degradation (17).

Given that information and accurate statistics on the prevalence of the problems associated with sleep disorders at factories is not available and more evidence are related to another jobs such as nursing, therefore, the primary goal of this study was to determine the prevalence of sleep disorders by focusing on insomnia in shift workers and its relation and effect on their quality of life at a textile factory.

\section{Methods}

This was a cross-sectional study with descriptive- analytical conditions in which the total number of staff working in rotating shifts at Kavir textile factory in Semnan, Iran, in 2016 was investigated based on census approach to sampling. The research project and questionnaire were reviewed and approved by the ethical committee at Semnan University of Medical Sciences. Inclusion criteria for the study were as follow: one year of work experience, having at least 6 months of recent rotation shift experience, consent to participate in the study, and having reading and writing literacy. Exclusion criteria were psychiatric and neurological diseases, and incomplete questionnaires. Data were collected through questionnaires and necessary information about the aims of the research was provided to the participants by a trainer. The main questionnaire was the result of merging 3 questionnaires. The first part was related to the demographic characteristics, medical history, socioeconomic profile, and the profile relating to working conditions. The second part was Epworth sleepiness scale (ESS) that measures the degree of sleepiness during the day and consists of 8 questions, each question having 0 to 3 points. If the total score is 10 or less, it is normal, and the sum of the points higher than 10 indicates excessive daytime sleepiness (18). In this study, we used Persian ESS questionnaire, with the Cronbach's alpha of $87 \%$, and the content validity of the questionnaire was confirmed by a panel of 10 faculty members.

The third part of the questioner was devoted to the short form-36 health survey (SF-36), which assesses the health of workers according to their own concepts. The questionnaire includes 36 questions, which are divided in 8 parts. These parts include questions about vitality, physical activity, body pain, general view of the individual from the health, his performance in the roles assigned to him, his performance in his emotional roles, functions of a person in his social role, and mental health (19).

SF-36 scoring questionnaire was based on Likert scale so that 2 overall assessments of performance were provided. The total physical component score (PCS) measures the physical dimension of health and the total mental component score (MCS) measures the psychosocial health dimension. Scores ranges between 0 and 100, with the higher score indicating a better quality of life. We used the Persian version of SF-36 questionnaire. Validity and reliability of this questionnaire were approved in Iranian population in Montazeri et al. and Asghari et al. studies, with internal consistency ranging from 0.70 to 0.85 and intrarater reliability with an interval of one week ranging from 0.43 to $0.79(20,21)$.

Considering the inclusion and exclusion criteria and ethical considerations, the sample size based on 95\% confidence interval and $\alpha=0.05$ was 207. A total of 207 staff working at Kavir textile factory in Semnan filled out the questionnaires. In this study, 95\% confidence interval was calculated using Wald test (significant level at 0.05). To investigate the relationship among each of these independent variables and sleep quality, t test, Mann-Whitney, Pearson Chi-square, and if necessary Fisher's exact test were used. To implement the variables underlying the analysis, variance and regression methods were used. Data were analyzed using SPSS Version 19.

\section{Results}

In this study, a total of 207 workers filled out the questionnaires. Out of 207 participants, 45 (21.7\%) were male and 162 (78.3\%) were female. The mean \pm SD age of the participants was $25.71 \pm 4.38$ years. The youngest person was 17 and the oldest was 42 years old. The mean \pm SD number of family members (family size) was $3.34 \pm 1.63$. The most sparsely populated family included 1 person and the 
most densely populated family was 10 . Among the participants, 135 workers (65.2\%) owned their own house, and 72 (43.5\%) were renters. Also, 201 workers (97.1\%) were urban habitants and others were habitants in rural areas. Considering the education level of the participants in the study, according to data obtained from the questionnaires, 1 person was illiterate, 2 had elementary school degrees, 29 primary high school degree, 127 diplomas, 21 technicians, 23 undergraduate (bachelor), and 4 graduates (M.Sc. and Ph.D.). Of the 207 workers, 22 (10.6\%) worked in morning shifts, 1 worker $(0.5 \%)$ worked in night shifts, and 184 workers $(88.9 \%)$ worked in rotating shifts. In total, 14 persons (6.8\%) had a second job. Of the 207 participants, 2 had too much income and 44 (21.2\%) had sufficient income. Also, 121 (58.5\%) earned less than their need, and others (19.3\%) had much less than their need. According to data obtained from the questionnaires, no one used sleep drugs. Of the participants, 4 (1.9\%) smoked cigarettes and 2 (1\%) drunk alcohol. The most common underlying diseases was sleep disorders (4.8\%), followed by migraine (1.9\%), thyroid disorders (1.9\%), psychotic disorders (1\%), depressive disorder (1\%), neurological disease (1\%), and asthma (0.5\%). Table 1 demonstrates the mean \pm SD of the participations' total working hours in a week, shift work experiences, and working experience.

Table 1. Mean \pm SD of Participations' Total Working Hours in a Week, Shift Work Experiences and Working Experience

\begin{tabular}{lccc}
\hline Variable & Mean \pm SD & Minimum & Maximum \\
\hline Weekly working hours, $\mathbf{h}$ & $46.93 \pm 7.35$ & 12 & 60 \\
Shift works experience, $\mathbf{y}$ & $3.76 \pm 3.75$ & 1 & 24 \\
Working experience, $\mathbf{y}$ & $4.68 \pm 3.92$ & 1 & 24 \\
\hline
\end{tabular}

According to information gathered from the questionnaires, among workers the most sleep and wake up hours were $12 \mathrm{PM}$ and $10 \mathrm{AM}$, so that 87 participants (42\%) fell asleep at 12 PM and 66 (31.9\%) woke up at $10 \mathrm{AM}$. In total, 112 workers (54.1\%) had enough sleep more than 7 hours, and in contrast, 95 (45.9\%) had poor sleep (less than 7 hours); the mean of their sleep duration was 7.43 hours with the standard deviation of 1.71. Of the participants, 100 (48.3\%) had no problem with sleep onset, and in contrast, $12(5.8 \%)$ had too much trouble in sleep onset, $86(41.5 \%)$ had frequent awakening problems, while 16 workers (7.7\%) had much trouble, and $4(1.9 \%)$ of them had too much trouble with this condition. However, $84(40.6 \%)$ workers had no problem in their awakening, but 17 (8.2\%) had a lot of problem, and $10(4.8 \%)$ complained too much about this problem.

Table 2 displays a significant relationship between gender and risk of sleep problems in the participants so that being female was in line with an increased chance of sleep disorders in workers $(\mathrm{z}=3.12,95 \% \mathrm{CI}: 1.39,7.01, \mathrm{P}=0.006)$. A significant relationship was found between having problem in sleep onset and having sleeping problems $(\mathrm{z}=1.76$, $95 \% \mathrm{CI}=1.31,2.38, \mathrm{P}<0.001)$. Moreover, the relationship between frequent waking up in workers and having sleep problems was significant $(\mathrm{z}=2.56,95 \% \mathrm{CI}=1.77,3.69, \mathrm{P}$ $<0.001$ ). Also, a significant relationship existed between early waking and sleeping problems $(\mathrm{z}=1.51,95 \% \mathrm{CI}=1.16$, $1.97, \mathrm{P}=0.002$ ).

The information gathered from Epworth questionnaire showed that 85 workers (41.1\%) obtained the scores of 1 to $6,41(19.8 \%)$ the score of 7 to $8,81(39.1 \%)$ the score 8 to 7 , and 81 workers (39.1\%) the score of 9 to 24 .

There was an inverse and significant correlation between the quality of life and Epworth sleep score, meaning that by an increase in Epworth score, the quality of life decreased, and the quality of life improved by reduction in Epworth score (Table 3$)(\mathrm{r}=-0.5, \mathrm{P}<0.001)$.

The relationship between aging and increased risk of sleep problems did not exist. No relationship was observed between family size, the residence neighborhood, having a rental house, living in the village (vs. in the city) and education level with an increase in the risk of sleep problems $(\mathrm{P}>0.05)$. Also, rotating work shift and increased risk of sleep problems, smoking and alcohol consumption and increased risk of sleep problems and weekly work hours, shift work experience and work experience had not a significant relationship $(\mathrm{P}>0.05)$.

\section{Discussion}

The results of our study revealed reduced sleep quality and subsequently reduced quality of life in workers with shift work.

According to information obtained from Epworth questionnaire, approximately $40 \%$ of the participants suffered from excessive daytime sleepiness. In the study of Shao et al., most of shift work nurses had a problem with sleep (22). In Vallieres et al. study, insomnia in shift workers worsened certain physical and mental health problems in them and impaired their quality of life (23). In another study by Asaoka et al. conducted on 1202 nurses, the prevalence of insomnia was $24.4 \%$, they had lower healthrelated QOL, more severe depressive symptoms, and more errors than those without insomnia. In their study, working at night was associated with the occurrence of insomnia among shift working nurses on rapid rotation schedules (24). In Anbazhagan study, the prevalence of insomnia among nurses was $43.07 \%$. Anxiety and depression were found in 23 (17.6\%) and 31 (23.8\%) individuals, respectively. 
Table 2. Relationship Between Gender, Sleep Onset Trouble, Frequent Awakening, Early Awakening and Risk of Sleep Problems

\begin{tabular}{lccc}
\hline Variables & ZValue & Risk of Sleep Problems Confidence Interval & P Value \\
\cline { 3 - 4 } & & Minimum & 7.01 \\
\hline Female gender & 3.12 & 1.39 & 0.006 \\
Sleep onset trouble & 1.76 & 1.31 & 2.38 \\
Frequent awakening & 2.56 & 1.77 & 3.69 \\
Early awakening & 1.51 & 1.16 & 0.001 \\
\hline
\end{tabular}

Table 3. Correlation Between Quality of Life and Epworth Sleep Score

\begin{tabular}{lccc}
\hline Variables & Mean \pm SD & r & PValue \\
\hline Epworth score $(\mathbf{0}-\mathbf{2 4})$ & $7.75 \pm 4.31$ & -0.5 & $<0.001$ \\
$\begin{array}{l}\text { Quality of life total score }(\mathbf{0}- \\
\text { 100) }\end{array}$ & $69.83 \pm 13.3$ & & \\
\hline
\end{tabular}

Also, insomnia had a significant relationship with increasing age, more number of nights worked in a year, and longer duration of working hours (25). Fekedulegn et al. examined the association of shift work with sleep quality in police officers. The overall prevalence of poor sleep quality was 54\% and night and evening work schedules were associated with poor sleep quality (26). Nea et al. investigated the impact of shift work on the diet and lifestyle among 1300 workers. Overall, 34.3\% of the samples had adequate sleep. Individuals who had insufficient sleep had a more significant negative effect on their physical health, mental health, family, social life, physical activity, and overall quality of life (27). In a study done by Gholami et al. on shift nurses, the questionnaire average indicated low quality of life among the nurses. In this study, the lowest score was related to the role of limitations due to emotional problems and the highest score was related to physical performance (28). In Assarrodi et al. s' study, it was found that physical problems are less than mental health problems (29). Gumenyuk et al., in their study, concluded that workers with shift work disorder and night shift have specific deficits in neurophysiological activity in the attentional domain (30). Most of nurses working in shifts in the study of Majidi, reported the negative impact of shift work on their fatigue and health (31).

In this study, no strong relationship was found between aging and increased risk of sleep problems in participants. In a study done by Bjorvatn et al. and Flo et al., complaints related to sleep disorders had a direct relationship with aging $(32,33)$. Also the study developed jointly by researchers from University of Louis Pasteur in France and Shahid Beheshti University in Iran revealed that aging has an impact on the frequency of awakening, so that older age groups reported more difficulties in sleep continuity. According to this study, the ability to adjust to shift work, in particular night work, decreases with aging (34). According to our study, a significant relationship was found between gender and risk of sleep problems among the participants, meaning that being a female was associated increased risk of sleep disorders. However, the result of Paulson et al. study indicated that the prevalence of sleep disorders associated with shift work among female nurses is less than the male (33). Results of another study conducted in Japan confirmed our study; in that study the estimated incidence of sleepiness was higher in females rather than males. In our society, family and social duties including matters relating to housekeeping, and childcare that should be done by women can be effective in reducing the power to adapt to shifts in women (35). The results of our study, did not report any relationship among the level of education, having a second job, incompetent income, living in villages, family size, residence neighborhood, and having a rental home and the participants' increased risk of sleep problems. However, in some of these studies, these factors and their relationships with life quality were studied, and in a study done by Gholami et al., there was a link between housing ownership and quality of life (28). Aghamolaie et al. found a notable relationship among gender, age, education, and employment status with physical and psychological quality of life (36). According to our study, no relationship was found between the type of work shift (rotating shift) and the risk of sleep disorders. However, in the study of Ghaljaei et al. that was conducted on nurses, those who worked in fixed shifts had better public health levels and better sleep quality than nurses working in rotating shifts (37). In the study done by e Silva et al., a relationship was shown among abnormalities in daytime sleepiness, fatigue, digestive problems, mood swings, and negative impact on marital relations and individual rotating shifts (38).

According to our results, there was not any relationship among the hours of work per week, shift work, and work experience with an increased risk of sleep problems. 
Nevertheless, Bjorvatn et al. believed that nurses, who have more working experience in work shifts, are more compatible with shift works and offer fewer complaints related to shifts (32). In the Gholami's study that studied the quality of life among nurses, it was observed that working experience was inversely associated with psychological component of their life quality (28).

The results of our study revealed no association between cigarette smoking, drinking alcohol, and sleep medications and increased chances of sleep problems. However, some researchers demonstrated that smoking, drinking tea, coffee, and alcoholic beverages are more common among shift workers than day workers $(39,40)$. In these studies, the sample size of the study was much bigger than ours. Perhaps because of the small size in our study, the difference between smoking in shift workers and nonshift workers was not shown properly. However, Escriba et al. also found no relationship between shift works and sedative-hypnotic drugs (41).

In our study, a clear association was found between sleep duration and increased risk of sleep problems. Ghaljaei et al. study in Iran indicated a direct relationship between sleep duration and sleep quality, ie, those with higher average duration of sleep have a better sleep quality. Nonetheless, some researchers believe that there is a relatively poor relationship between sleep duration and sleep quality, because people are different in their need for sleep and sleep satisfaction (37).

The results of our study revealed a significant relationship among the problem of sleep onset, frequent waking from sleep, early waking, and the prevalence of sleep problems in shift workers. Soleimany et al., in their study, showed that all 3 parameters defining insomnia including the problem in sleep onset, early waking, and sleep continuity disturbance in the Shift workers are more common (42). However, no significant difference was reported in Ohida et al. study in sleep continuity disturbance among shift workers and non-shift workers (43).

Due to the many problems that shift work causes for an individual, it is recommended to design and implement intervention studies to evaluate the ways for improving sleep quality of shift workers, for example, the effect of rotating shifts pattern on sleep quality of workers. It is likely that people whose shift work changes monthly can adapt to their work condition better than those whose shift work changes weekly because their body has more time to adjust their circadian rhythm to work times. Thus, in a new study, the relationship between the time duration when a person works in a particular shift and the incidence of sleep disorders can be examined. The effect of reducing the duration of each shift, for example, from 12 hours to 8 hours, or using 24 hours of leave after every night shift and their effects on sleep disorders can also be a useful study topic in this field. Investing in health and medical services for shift workers and screening tests and periodic medical examination to discover common problems in shift work are also of particular importance. Today, most researchers believe that adverse effects and complications of shift works are reduced compared to the past. This can be due to a substantial improvement of working conditions, particularly in developed countries as well as faster diagnosis and treatment of physical ailments than before. However, the creation of work medicine and attention of health care system to people working in shifts have a decisive role in their health condition (44).

\subsection{Limitations}

This study had several limitations including selfreporting of sleep disorders and quality of life with unclear oversight, which can affected the recorded data.

\subsection{Conclusion}

Shift work conditions may enhance sleep disorders. However, our data should alert occupational health physicians for the diagnosis and prevention of possible undetected intrinsic sleep disorders, which could possibly worsen shift workers' health. Although an ideal shift system does not exist, a holistic approach comprising education of managers, employees, and their families can ameliorate some of the health consequences.

\section{Acknowledgments}

The authors would like to kindly thank managers of Kavir factory and clinical research development unit (CRDU) Kowsar hospital, Semnan, Iran.

\section{Footnotes}

Authors' Contribution: Substantial contributions to the conception or design of the work, the acquisition, analysis, or interpretation of data for the work, Daryoush Pahlevan, Abolfazl Abdoallahpour, Kamran Ghods, Majid Mirmohammadkhani; drafting the work or revising it critically for important intellectual content, Kamran Ghods, Mina Ahmadi, Daryoush Pahlevan; final approval of the version to be published, Daryoush Pahlevan, Abolfazl Abdoallahpour, Mina Ahmadi, Alireza Emadi, Majid Mirmohammadkhani, Ali gohari, Kamran Ghods.

Competing Interests: None declared.

Data Sharing Statement: No additional data available. Funding/Support: None declared. 


\section{References}

1. Mayo E. The social problems of an industrial civilisation. Routledge; 2014.

2. Vyas MV, Garg AX, Iansavichus AV, Costella J, Donner A, Laugsand LE, et al. Shift work and vascular events: systematic review and meta-analysis. BMJ. 2012;345:e4800. doi:10.1136/bmj.e4800. [PubMed: 22835925].

3. Farzianpour F, Nosrati SA, Foroushani AR, Hasanpour F, Jelodar ZK, Keykale MS, et al. Relationship Between Shift Work and Personality Traits of Nurses and Their Coping Strategies. Glob J Health Sci. 2015;8(5):166-74. doi: 10.5539/gjhs.v8n5p166. [PubMed: 26652076].

4. Staufenbiel SM, Penninx BW, Spijker AT, Elzinga BM, van Rossum EF. Hair cortisol, stress exposure, and mental health in humans: a systematic review. Psychoneuroendocrinology. 2013;38(8):1220-35. doi: 10.1016/j.psyneuen.2012.11.015. [PubMed: 23253896].

5. Loudoun RJ, Muurlink O, Peetz D, Murray G. Does age affect the relationship between control at work and sleep disturbance for shift workers?. Chronobiol Int. 2014;31(10):1190-200. doi: 10.3109/07420528.2014.957307. [PubMed: 25231503].

6. Linton SJ, Kecklund G, Franklin KA, Leissner LC, Sivertsen B, Lindberg E, et al. The effect of the work environment on future sleep disturbances: a systematic review. Sleep Med Rev. 2015;23:10-9. doi: 10.1016/j.smrv.2014.10.010. [PubMed: 25645126].

7. Guo Y, Liu Y, Huang X, Rong Y, He M, Wang Y, et al. The effects of shift work on sleeping quality, hypertension and diabetes in retired workers. PLoS One. 2013;8(8):e71107. doi: 10.1371/journal.pone.0071107. [PubMed: 23976988].

8. Eldevik MF, Flo E, Moen BE, Pallesen S, Bjorvatn B. Insomnia, excessive sleepiness, excessive fatigue, anxiety, depression and shift work disorder in nurses having less than 11 hours in-between shifts. PLoS One. 2013;8(8):e70882. doi: 10.1371/journal.pone.0070882. [PubMed: 23976964].

9. Isikhan V, Guner P, Komurcu S, Ozet A, Arpaci F, Ozturk B. The relationship between disease features and quality of life in patients with cancer-I. Cancer Nurs. 2001;24(6):490-5. doi: 10.1097/00002820200112000-00012. [PubMed: 11762512].

10. Schwartz JR, Roth T. Shift work sleep disorder: burden of illness and approaches to management. Drugs. 2006;66(18):2357-70. doi: 10.2165/00003495-200666180-00007. [PubMed: 17181377].

11. Wright KJ, Bogan RK, Wyatt JK. Shift work and the assessment and management of shift work disorder (SWD). Sleep Med Rev. 2013;17(1):41-54. doi: 10.1016/j.smrv.2012.02.002. [PubMed: 22560640].

12. Gumenyuk V, Belcher R, Drake CL, Roth T. Differential sleep, sleepiness, and neurophysiology in the insomnia phenotypes of shift work disorder. Sleep. 2015;38(1):119-26. doi: 10.5665/sleep.4336. [PubMed: 25325466].

13. Akerstedt T, Wright KJ. Sleep Loss and Fatigue in Shift Work and Shift Work Disorder. Sleep Med Clin. 2009;4(2):257-71. doi: 10.1016/j.jsmc.2009.03.001. [PubMed: 20640236].

14. Cuesta M, Boudreau P, Dubeau-Laramee G, Cermakian N, Boivin DB. Simulated Night Shift Disrupts Circadian Rhythms of Immune Functions in Humans. J Immunol. 2016;196(6):2466-75. doi: 10.4049/jimmunol.1502422. [PubMed: 26873990].

15. Zee PC, Attarian H, Videnovic A. Circadian rhythm abnormalities. Continuum (Minneapolis, Minn). 2013;19(1 Sleep Disorders):132-47.

16. Abbott SM, Reid KJ, Zee PC. Circadian Rhythm Sleep-Wake Disorders. Psychiatr Clin North Am. 2015;38(4):805-23. doi: 10.1016/j.psc.2015.07.012. [PubMed: 26600110].

17. Costa G. Shift work and occupational medicine: an overview. Occup Med (Lond). 2003;53(2):83-8. doi: 10.1093/occmed/kqg045. [PubMed: 12637591].

18. Johns MW. A new method for measuring daytime sleepiness: the Epworth sleepiness scale. Sleep. 1991;14(6):540-5. doi: 10.1093/sleep/14.6.540. [PubMed: 1798888].
19. McHorney CA, Ware JJ, Raczek AE. The MOS 36-Item Short-Form Health Survey (SF-36): II. Psychometric and clinical tests of validity in measuring physical and mental health constructs. Med Care. 1993;31(3):24763. doi: 10.1097/00005650-199303000-00006. [PubMed: 8450681].

20. Montazeri A, Goshtasebi A, Vahdaninia M, Gandek B. The Short Form Health Survey (SF-36): translation and validation study of the Iranian version. Qual Life Res. 2005;14(3):875-82. doi: 10.1007/s11136-004-10145. [PubMed: 16022079].

21. Asghari A, Faghehi S. Validation of the SF-36 health survey questionnaire in two Iranian samples. J Daneshvar Raftar. 2003;1:1-11.

22. Shao MF, Chou YC, Yeh MY, Tzeng WC. Sleep quality and quality of life in female shift-working nurses. J Adv Nurs. 2010;66(7):1565-72. doi: 10.1111/j.1365-2648.2010.05300.x. [PubMed: 20492021].

23. Vallieres A, Azaiez A, Moreau V, LeBlanc M, Morin CM. Insomnia in shift work. Sleep Med. 2014;15(12):1440-8. doi: 10.1016/j.sleep.2014.06.021. [PubMed: 25277664].

24. Asaoka S, Aritake S, Komada Y, Ozaki A, Odagiri Y, Inoue S, et al. Factors associated with shift work disorder in nurses working with rapid-rotation schedules in Japan: the nurses' sleep health project. Chronobiol Int. 2013;30(4):628-36. doi: 10.3109/07420528.2012.762010. [PubMed: 23445510].

25. Anbazhagan S, Ramesh N, Nisha C, Joseph B. Shift work disorder and related health problems among nurses working in a tertiary care hospital, Bangalore, South India. Indian J Occup Environ Med. 2016;20(1):35-8. doi: 10.4103/0019-5278.183842. [PubMed: 27390478].

26. Fekedulegn D, Burchfiel CM, Charles LE, Hartley TA, Andrew ME, Violanti JM. Shift Work and Sleep Quality Among Urban Police Officers: The BCOPS Study. J Occup Environ Med. 2016;58(3):e66-71. doi: 10.1097/JOM.0000000000000620. [PubMed: 26949891].

27. Nea F, Poushahidi K, Corish C, Kearney J, Livingstone B, Bassul C. Circadian disruption in shift workers - the effects of insufficient sleep on dietary and lifestyle behaviours. Proc Nutr Soc. 2016;75(OCE1) doi: 10.1017/s0029665115004681.

28. Gholami A, Farsi M, Hashemi Z, Lotfabadi P. Quality of life in nurses working in neyshabur hospitals. Thrita J Med Sci. 2012;1(3):94-100. doi: 10.5812/thrita.7384.

29. Assarrodi A, Golafshani A, Akaberi S. The relationship between spiritual well-being and quality of life in nurses. J North Khorasan Univ Med Sci. 2012;3(4):10.

30. Gumenyuk V, Howard R, Roth T, Korzyukov O, Drake CL. Sleep loss, circadian mismatch, and abnormalities in reorienting of attention in night workers with shift work disorder. Sleep. 2014;37(3):545-56. doi: 10.5665/sleep.3494. [PubMed: 24587577].

31. Majidi SA, Masoudi I, Moghadamnia MT, Sharifi M, Barzegar M. A survey of physical, psychological, and social health indices in shift working nurses. Int J Hospital Res. 2014;3(4):193-8.

32. Bjorvatn B, Dale S, Hogstad-Erikstein R, Fiske E, Pallesen S, Waage S. Self-reported sleep and health among Norwegian hospital nurses in intensive care units. Nurs Crit Care. 2012;17(4):180-8. doi: 10.1111/j.14785153.2012.00504.x. [PubMed: 22698160].

33. Flo E, Pallesen S, Mageroy N, Moen BE, Gronli J, Hilde Nordhus I, et al. Shift work disorder in nurses-assessment, prevalence and related health problems. PLoS One. 2012;7(4):e33981. doi: 10.1371/journal.pone.0033981. [PubMed: 22485153]

34. Saremi M, Tassi P. Comparison of fatigue level, sleep quality and quantity in old and young shift workers [In Persian]. Res Med. 2008;32(2):135-9.

35. Doi Y, Minowa M. Gender differences in excessive daytime sleepiness among Japanese workers. Soc Sci Med. 2003;56(4):883-94. doi: 10.1016/S0277-9536(02)00089-8. [PubMed: 12560020].

36. Aghamolaei T, Tavafian SS, Zare S. Determinants of health related quality of life on people living in bandar abbas, iran. Iran J Public Health. 2011;40(3):128-35. [PubMed: 23113095].

37. Ghaljaei F, Naderifar M, Ghaljeh M. Comparison of general health status and sleep quality between nurses with fixed working shifts and 
nurses with rotating working shifts [In Persian]. Zahedan JRes Med Sci. 2011;13(1):47-50.

38. e Silva LO, Esteves AM, Alves NNL, da Silva AN, Carvalho FVN, Bittencourt LRA, et al. Mood, sleep patterns and the effect of physical activity on the life quality of brazilian train operators. Sleep Sci. 2012;5(4):1139.

39. Harma M, Tenkanen L, Sjoblom T, Alikoski T, Heinsalmi P. Combined effects of shift work and life-style on the prevalence of insomnia, sleep deprivation and daytime sleepiness. Scand JWork Environ Health. 1998;24(4):300-7. doi: 10.5271/sjweh.324. [PubMed: 9754862].

40. Fido A, Ghali A. Detrimental effects of variable work shifts on quality of sleep, general health and work performance. Med Princ Pract. 2008;17(6):453-7. doi: 10.1159/000151566. [PubMed: 18836273].
41. Escriba V, Perez-Hoyos S, Bolumar F. Shiftwork: its impact on the length and quality of sleep among nurses of the Valencian region in Spain. Int Arch Occup Environ Health. 1992;64(2):125-9. doi: 10.1007/BF00381480. [PubMed: 1399022].

42. Soleimany M, Nasiri Ziba F, Kermani A, Hosseini F. Comparison of sleep quality in two groups of nurses with and without rotation work shift hours [In Persian]. Iran J Nurs. 2007;20(49):29-38.

43. Ohida T, Kamal AMM, Sone T, Ishii T, Uchiyama M, Minowa M, et al. Night-shift work related problems in young female nurses in Japan. $J$ Occup Health. 2001;43(3):150-6. doi:10.1539/joh.43.150.

44. Mills ME, Arnold B, Wood CM. Core-12: a controlled study of the impact of 12-hour scheduling. Nurs Res. 1983;32(6):356-61. doi: 10.1097/00006199-198311000-00008. [PubMed: 6567857]. 